\title{
Dimensiones simbólicas inscritas en el trabajo en la danza clásica escénica: experiencia(s) desde el cuerpo del bailarín
}

\author{
Symbolic dimensions inscribed in ballet dance labour: experiences from the body of the dancer
}

Tanya García-López ${ }^{a}$

\begin{abstract}
:
The bodies of the dancers that move in the classical dance field are located in the intersection of the memory of the individ ual body and the collective body; in this network of fights between the self and the other, the research has set as general objective an approach to the field of classical dance towards the body of the dancer, in order to apprehend the meanings that are elaborated dialec tally in the social phenomena of dance labour. In consideration of this prior ideas, the experiences of nine classical dancers in Mexico City were reconstructed, these experiences were weaved towards the theory, considering essentially two dimensions: habitus and field; the family, school and labour as institutions where the habitus of the subject is conformed, and the profession of the dancer, comprehend as the field. In this analysis several variables were recognized, such as process of constitution of the field, meaning of the body in classical dance, discipline and pain as symbols in the field, permanent vigilance over the body, among others; which combined can improve the understanding towards the matter of study.
\end{abstract}

\section{Keywords:}

Ballet, dance history, dance labour, embodied culture.

\section{Resumen:}

Los cuerpos de los bailarines que se mueven dentro del campo de la danza clásica escénica se encuentran en la intersección de la memoria del cuerpo individual y el cuerpo colectivo; en este entramado de luchas entre el yo y el otro, la investigación se propone como objetivo general aproximarse al campo de la danza clásica a través del cuerpo del bailarín, para aprender los significados que se elaboran dialécticamente en el hecho social del trabajo en la danza. Con base en lo anterior, se reconstruyeron las experiencias de nueve bailarines de danza clásica en la Ciudad de México, las cuales se entretejieron con la teoría, considerando dos dimensiones esencialmente: habitus y campo; la familia, la educación y el trabajo como instituciones en las cuales se conforma el habitus del sujeto; y la profesión del bailarín, comprendida como campo. En este análisis se reconocieron varias nociones que permiten mejorar la comprensión sobre objeto de estudio, tales como el proceso de constitución del campo, la significación del cuerpo en la danza clásica escénica, disciplina y dolor como símbolos dentro del campo, vigilancia permanente del cuerpo, entre otros.

\section{Palabras Clave:}

Ballet, historia de la danza, trabajo en la danza, cultura corporeizada.

\section{Introducción}

Investigar danza es danzar en la realidad, y con ello enunciar los matices que se dibujan en ella; la danza en este sentido, se vuelve una metáfora que se libera de lo sublime.

A partir del 2019 en la Ciudad de México, artistas escénicos han creado múltiples espacios de diálogo y acción, como foros, reuniones con instituciones gubernamentales, y manifestaciones, para enunciar, y con ello mejorar las condiciones laborales; pues se reconoce la desvalorización del trabajo del artista escénico, fenómeno que se sintetiza en precariedad y se materializa en la ausencia de derechos laborales; en este contexto, indagar sobre el trabajo en la danza resulta necesario.

Particularmente, sobre el trabajo en la danza clásica se debe decir que es un objeto de estudio con poca evidencia cuantitativa, ya que se observa un mutismo sistemático dentro de los datos estadísticos de

Autor de Correspondencia, Universidad Autónoma del Estado de Hidalgo, https://orcid.org/0000-0001-7225-5844, Email: 
instituciones gubernamentales; evidenciando así, de forma sintética, la necesidad de estadísticas específicas sobre la profesión; y ciertamente, se comprende la invisibilización de quienes se desarrollan en esta esfera.

Por otro lado, cuestionar la dimensión cualitativa del trabajo en la danza clásica escénica es un tema aún en desarrollo, ya que no se encuentran investigaciones científicas en México -a excepción de los estudios realizados por Fernández (2007) en danza contemporánea en la Ciudad de México, y Solís y Brijandez (2018) en danza contemporánea y clásica en Tijuana- que describan cómo se configura el campo, la interacción de los sujetos (relaciones de poder), las problemáticas de la profesión, entre otras variables; las cuales en su conjunto, acerquen a la comprensión de la profesión del bailarín de danza clásica escénica.

Esta premisa es la génesis de la investigación: estudiar el campo de la danza clásica, es decir, pensar en los cuerpos, quiénes y cómo. Elaborar una cartografía del bailarín de danza clásica, que permita conocer ¿cómo se describen a sí mismos como trabajadores? ¿cuáles son las prácticas? ¿cuáles son las representaciones sobre el campo del bailarín de danza clásica? ¿cuáles son las estrategias del sujeto para movilizarse en el campo? en otras palabras, la obtención de una visión reflexiva de los significados que se inscriben en la profesión del bailarín.

En este sentido, el objetivo general de la investigación es aproximarse al campo de la danza clásica a través del cuerpo del bailarín, para aprender los significados individuales y colectivos, que se elaboran dialécticamente en el hecho social del trabajo en la danza. Acerca de los objetivos específicos: reconocer las condicionantes históricas de las acciones y prácticas actuales; documentar a profundidad la experiencia de bailarines de danza clásica escénica, a través de la elaboración de trayectorias laborales, para conocer las representaciones, sentimientos y experiencias que se circunscriben al trabajo y describir el trabajo en el campo de la danza clásica escénica, para obtener información sobre las características objetivas del campo.

\section{Encontrando formas de movimiento: metodología}

El método de la investigación es cualitativo, pues se tiene como propósito la expansión de los contornos de la realidad, favoreciendo así la comprensión del objeto de estudio en su complejidad. La investigación posee un componente documental y uno empírico; para el componente documental se realizó: un análisis sobre la conformación del campo de la danza clásica, de forma general; y un marco teórico, en el que se conceptualiza la cultura, así como las implicaciones de la teoría de la acción de Pierre Bourdieu, proposiciones sobre la legitimación e institucionalización en el campo de la danza desde Peter L. Berger y Thomas Luckmann; y aprehensiones antropológicas sobre el cuerpo de André Le Breton y Marcel Mauss.

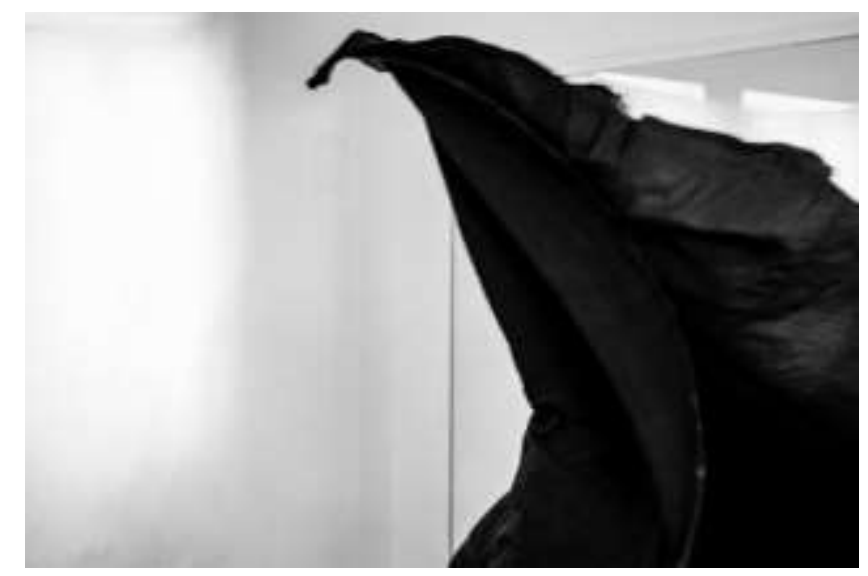

Desdoblamientos a partir de la multiplicidad del cuerpo en la imagen de Diana Áviles Samperio (2020).

Acerca del componente empírico, se elaboraron nueve trayectorias laborales de bailarines de danza clásica escénica, a partir de las cuales se buscó la interpretación de las objetivaciones significativas expresadas para la búsqueda de la experiencia subjetiva; develando así los "planos subcutáneos de la estructura" (Turner, 2008, p. 76); de las individualidades y colectividades. Cabe decir, que la investigación se realizó con bailarines con residencia en la Ciudad de México, de los cuales 6 son mujeres y 3 son hombres; de ellos, 6 son bailarines activos y 3 son bailarines retirados, por lo que el rango de edad es variable, de 28 a 60 años. De los bailarines entrevistados, algunos pertenecen o pertenecieron a la Compañía Nacional de Danza, el Taller Coreográfico de la Universidad Nacional Autónoma de México, la Compañía Ardentía, el Ballet de la Ciudad de México; o bailaron como independientes.

El espacio geográfico del estudio, como se ha mencionado, es la Ciudad de México, pues en esta ciudad se concentran mayoritariamente los grupos artísticos del país, y la infraestructura para el desarrollo de actividades artísticas es mayor en comparación con otros estados del país; la Ciudad de México cuenta con 111 auditorios y 156 teatros (Sistema de Información Cultural México, 2018).

Para la investigación se utilizó como técnica la entrevista a profundidad, pues se concibe como la creación de un espacio para la convergencia de las experiencias, del investigador y el sujeto de estudio; que permite el acercamiento a la dimensión individual y social de ambos. Finalmente, a partir de la información, se realizó un análisis del discurso en su vertiente cualitativa; reconstrucción para el grato encuentro con una realidad 
mutable y plagada de posibilidades, para hallar más preguntas que absolutos.

\section{Herencias y memorias del campo de la danza clásica: algunas notas sobre su conformación}

Estudiar la conformación del campo de la danza clásica escénica es un primer paso para comprender los significados que se juegan dentro del mismo, es por ello que en este análisis inicial se buscó indagar sobre las experiencias de quienes han danzado y constituido el campo, movimientos y experiencias que habitan las hojas de los libros, y que ciertamente, se mueven dentro de los cuerpos de quienes hoy danzan; trascendiendo la conceptualización tradicional de la temporalidad, estos bailarines cohabitan el campo de la danza clásica; un intersticio entre la memoria colectiva y la memoria individual.

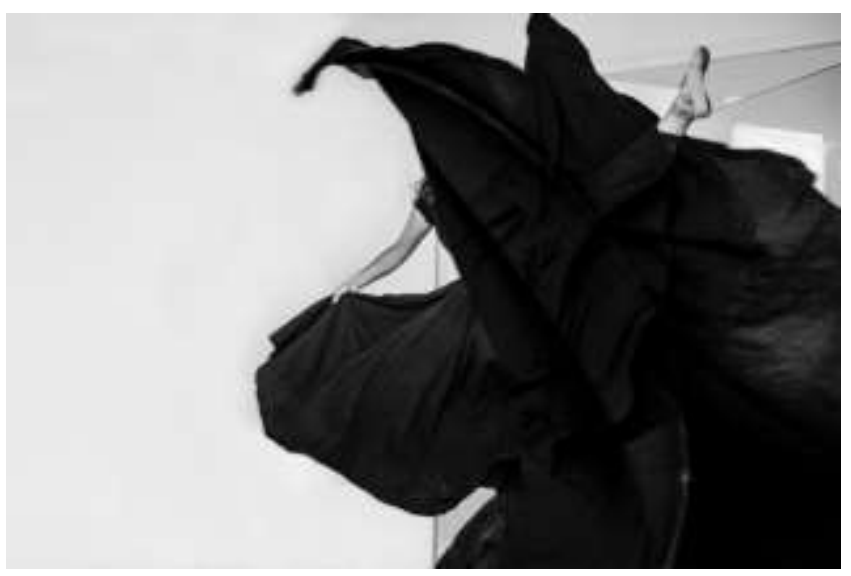

Desdoblamientos a partir de la multiplicidad del cuerpo en la imagen de Diana Áviles Samperio (2020).

Ahora bien, para este análisis es pertinente realizar una acotación para describir la constitución de universos simbólicos desde la teoría de Berger y Luckmann (2003). Para estos autores, las actividades que realiza el ser humano en la esfera social son susceptibles a la habituación, proceso que sirve como mecanismo para la economía de esfuerzos, y que evita la repetición infinita de procedimientos dificultosos y que, de cierta forma, conllevan a la síntesis de hábitos. Particularmente, estos hábitos poseen un significado para los sujetos del campo en el que se desarrollan: "se incrustan como rutinas en su depósito general de conocimientos que da por establecido"(Op. Cit., p. 72), y por ello, el acceso al origen de los hábitos no se puede realizar a través de la memoria del sujeto individual, sino más bien a través de la memoria del sujeto colectivo.

La sucesión o complejización de la habituación resulta en la in stitucionalización; proceso en el que una comunidad de sujetos reconoce un conjunto de hábitos, que son realizados a su vez, por un subgrupo de sujetos en particular; entre las características de las instituciones se reconoce que son construcciones históricas y que sirven como mecanismos de control social. Cabe mencionar, que estas instituciones evolucionan a través de la objetivación, es decir, "se experimentan ahora como si poseyeran una realidad propia, que se presenta al sujeto como un hecho externo y coercitivo" (Op. Cit., p. 78), es decir, una economización del esfuerzo que resulta en la práctica inconsciente de un conjunto de hábitos, y que produce una interacción retroactiva entre la externalización y la objetivación, el sujeto y la sociedad.

De la institucionalización deviene la legitimación, que se comprende como los "modos con que poder 'explicarse' y justificarse'" (Op. Cit., p. 82); Berger y Luckmann lo argumentan como una dimensión cognitiva y normativa que protege a la institución, y que se configura a través del lenguaje. Esto se puede materializar en el conocimiento primario de la institución (sistema axiológico, criterios para la regulación del comportamiento, definición de roles, control sobre los sujetos, entre otros) y el conocimiento o corpus propio de la institución.

En este sentido, emerge el lenguaje, que para los autores "objetiva las experiencias compartidas y las hace accesibles a todos los que pertenecen a la misma comunidad lingüística, con lo que se convierte en base e instrumento del acopio colectivo del conocimiento" (Op. Cit., p. 89). Además, a esta nebulosa de signos y significados se suma, que se reconocen otros elementos para la legitimación de un campo, tales como la utilización de objetos simbólicos o acciones para reafirmarse; en otras palabras, la reproducción de ciertas acciones significativas o uso de objetos. Otro aspecto es la definición de roles, los cuales contribuyen al orden institucional a través del reconocimiento de la función propia y la función del otro, lo que propicia la continuación de la construcción subjetiva de esta realidad.

A modo de nota, en este proceso es posible que se produzca la reificación: "un paso extremo en el proceso de la objetivación, por el que el mundo objetivado pierde su comprensibilidad como empresa humana y queda fijado como factibilidad inerte, no humana y no humanizable" (Op. Cit., p. 115); en otras palabras, aquello parece como inamovible y fijado naturalmente.

Acerca de la legitimación, como se ha establecido, es una objetivación ciertamente con mayor sofisticación, en la que la institución se encuentra "objetivamente disponible y subjetivamente plausible" (Op. Cit., p. 119); es decir, conjuga la objetivación, la sedimentación y la acumulación del conocimiento. Sin embargo, cuando el campo adquiere suficiente autonomía, se constituye en un universo simbólico; y que para Berger y Luckmann (2003), es concebido como una "matriz de todos los 
significados objetivados socialmente y subjetivamente reales; toda la sociedad histórica y la biografía de un individuo se ven como hechos que ocurren dentro de ese universo" (Op. Cit., p. 123). Dentro de este universo simbólico se ordenan y legitiman los roles, mecanismos de control y vigilancia, lo valioso, las formas de hacer, el orden de la historia, el presente, y ciertamente se anticipa las posibles formas del futuro.

Los párrafos anteriores permiten anticipar la progresiva constitución del campo de la danza clásica escénica, no obstante, es pertinente dar movimiento a estos conceptos. Para comenzar, se considera que la danza como categoría general, se encuentra en la intersección de la condición humano y la realidad social, entre el yo y el otro; "danza que respira la polisemia de un ambiente que es producción permanente de semiosis, el cuerpo humano que baila y que como todas las criaturas que mezclan suelo con estrellas, necesita fábricas semánticas" (Katz, 2015, p. 16), danza como objetivación y como manifestación del espíritu de la realidad cultural, y por tanto, ordenada en un eje temporal y espacial particular. La premisa, permite derrumbar la idea que reduce la danza a un lenguaje universal, "que atraviesa todas las diferencias y se traduce traslúcidamente" (Op. Cit., p 23), o la concepción naturalista de la danza como lenguaje corporal, en la que se aborda el cuerpo con sus brotes naturales de lenguaje.

El campo de la danza clásica escénica inicia su constitución entre el siglo XV y XVII, momento en el que comienza la modernidad occidental europea, como resultado de la disipación del feudalismo y la predominancia del cristianismo. En este contexto surgen los primeros registros dancísticos, a partir de la redefinición de los signos y códigos del cuerpo (Andrella, 2010); a la vez, que la danza y el cuerpo que danza, se relacionan con la vida social y la ritualidad. De forma simultánea, en este momento, se produce la profesionalización en la danza a partir del reconocimiento de un espacio específico para danzar, la emergencia de la coreografía y la división social del trabajo, Dallal argumenta: "bailarán los capacitados para danzar, los que se han preparado largamente para hacerlo, los que han sido enseñados por los sacerdotes y guerreros y han permanecido viviendo en el ámbito sagrado" (1997, p. 19), cabe mencionar, que este proceso es denominado secularización. Las ideas anteriores, muestran la presencia de mecanismos de control sobre el cuerpo que danza, que en este momento histórico subyacen en el pensamiento cristiano.

Particularmente, en el siglo XVI la danza presenta dos formas, comprendida como actividad pagana y como proceso de aculturación de la danza hegemónica. Por su parte, el cuerpo se comprende a partir de la concepción griega sobre la maldad inscrita en el cuerpo del ser humano, lo cual resulta en la instrumentalización del cuerpo para la elevación cultural a través de la negación, que es comprendida como la imposibilidad de salir del cuerpo controlado; para Andrella "el cuerpo como libro es censurado, quemado, excluido, y el conocimiento, mutilado del componente de la experiencia corporal" (2010, p. 31). En este entendido la cultura dominante estableció los mecanismos de control sobre el cuerpo, y cerró los agujeros orgánicos y semánticos del cuerpo para domesticarlo; dando así lugar a la apropiación de la danza como campo social para la expresión, expresión comprendida al margen de la cultura en la que se inscribe.

A modo de nota, la concepción instrumental del cuerpo, aún después de cinco siglos, es latente en los espacios educativos y profesionales de la danza académica; y dicha concepción, atiende a un proceso de legitimación del sujeto para ingresar y permanecer en el campo, y que se concreta en el trato hacia el cuerpo en diferentes dimensiones; u na particularmente interesante, es hacia el dolor como muestra la evidencia empírica del presente estudio.

Continuando con el trazo histórico, la danza de carácter ritual que se observa en el cristianismo desaparece, puesto que se considera transgresora, y se penaliza el cuerpo y la experiencia de su vivencia en el mundo real, pues resulta indomable y posibilita la entrada y salida de la maldad; ahora, la palabra y lo escrito, se convierten en el medio para acceder a lo sagrado, y la danza, transita hacia el ámbito de las actividades educativas y nobilizantes. Un ejemplo de lo anterior, es el Curam illiius habe de Antonio de Florencia publicado en 1472, en el que se establecían las normas sobre el tiempo del ser humano, y su clasificación: festivo y cotidiano (Andrella, 2010). No obstante, a pesar de estos controles sociales, en las danzas festivas explotaba la represión, y se jugaba con lo permitido y lo prohibido. El juego, la música, la alegría y la ritualidad expresiva, permeaban la vida: "y todo el año el pueblo se recrea bailando y danzando" (Zuccaro, 1608, p. 14 en Andrella, 2010, p. 64).

La progresiva separación de la ritualidad y la vida comunitaria, posibilitó la emergencia de la danza como campo estético, o, en otras palabras, como un arte (Ferreiro, 2005); en consecuencia, en el siglo XVII germina la danza académica o escénica: "en la que hay una intención consciente y deliberada de ciertos sujetos de producir experiencias estéticas" (Op. Cit., p. 72). La danza académica se percibió como una actividad cortesana, y su enseñanza-aprendizaje hizo manifiesta la necesidad de sistematizar los hábitos dancísticos, que se materializaron en los primeros tratados de danza escénica. Lo anterior, dirige el pensamiento al concepto 
de legitimación que previamente se ha expuesto, puesto que se observa la necesidad de plasmar a través del lenguaje los hábitos de quienes danzaban, y que a su vez muestra, una diferenciación de quienes realizaban esta actividad; y no menos, un sistema axiológico. Para ilustrar lo anterior, en el sigloXIV el aprendizaje del balletera una etiqueta de género, y a su vez, símbolo de decoro y educación (Pickard, 2015); no obstante, esto marcó el inicio de las construcciones de género en la danza clásica, y la pronunciada dicotomía entre lo femenino y lo masculino, y que se observa en la caballerosidad del hombre y la femineidad de la mujer en el pas de deux (baile de pareja), o el decoro entre bailarines -ambos ejemplos dentro del repertorio clásico-.

Mención especial requieren los tratados de danza escénica, los cuales se clasifican de acuerdo a la región en la que fueron escritos: franco-borgoñesa y lombarda o italiana; siguiendo a Sylvia Ramírez, algunos tratados del siglo XV son el de Domenico da Piacenza, Antonio de Cornazano y Guglielmo Ebreo. Se resalta que, en estos documentos, se establecieron los principios estéticos y filosóficos, abordando temáticas como la relación entre la técnica y la expresividad (Ferreiro, 2005).

Posteriormente, en 1661 se funda la Real Academia de Danza en Francia, espacio en el que aparecerían las posiciones abiertas de la danza clásica (Ferreiro, 2005); aparece el primer sistema de notación de Charles-LouisPierre de Beauchamps y Raoul-Auger Feuillet, y se establece el francés para la codificación de la danza clásica, se definen las posiciones elementales y otros pasos; que se sintetizarán en el texto Coreografía del arte de escribir danzas de caracteres, figuras y signos demostrativos publicado en 1706; se observa cómo de forma progresiva se consolida la institucionalización del campo de la danza clásica.

Estas primeras posiciones se pueden analizar a partir del concepto de técnica corporal de Marcel Mauss, para quien es la "forma en la que los hombres, sociedad por sociedad, hacen uso de su cuerpo en una forma tradicional" (1979, p. 337), intersección biológica, psicológica y sociológica. Técnica que se aprendetransmite-adquiere a través del cuerpo, y que conforma el cuerpo del bailarín, y que no se limita a la repetición y dominio de la técnica; sino que implica la compleja existencia/experiencia del cuerpo, y sus múltiples posibilidades de movimiento en el tiempo y el espacio; se observa, como la técnica corporal y el lenguaje, vinculan la experiencia individual con la experiencia colectiva accesible. Cabe decir, que el lenguaje se presenta como un control social para los futuros herederos del campo, control que se hereda e inscribe en el cuerpo, y simultáneamente, se reproduce. Esta última idea, se ilustra con el libro Maestro de danza de Pierre Rameau en 1725, en el que se describen las calidades del movimiento, posiciones, comportamiento, entre otros.

Para el siglo XVIII, la danza fortalecerá su autonomía como campo a partir del ballet de acción y la inserción de la pantomima, movimiento iniciado por Franz Hilverding (Ramos, 2002a), y después, desarrollado por Gasparo Anglioni y Jean-Georges Noverre. Otro aspecto importante, será la definición de roles, los cuales contribuyen al orden institucional, a través del reconocimiento del rol propio y del rol del otro, lo que permite una construcción subjetiva de esta realidad; y que particularmente se puede comprender a partir de la práctica clasificatoria de los bailarines con base en su físico, técnica y temperamento (Ramos, 2002a) durante este momento histórico. Cabe señalar, que es una práctica vigente en la mayoría de las compañías de danza clásica estudiadas, que, si bien no se realiza con base en el temperamento, sí se considera el capital físico, artístico y técnico --estas variables del capital son retomadas de las investigaciones realizadas por Wainwright et al. (2006), sobre el habitus del bailarín de danza clásica en compañías europeas-. Estas líneas, muestran la adquisición de conciencia sobre las posibilidades estéticas del cuerpo, que menciona Roxana Ramos (2009), y con ello, la selectividad de quienes pueden ser bailarines y quienes no.

Ya para el siglo XIX, se configura el periodo preromántico, la técnica corporal de la danza clásica continua su consolidación y las puntas hacen su debuten los escenarios parisinos. Posteriormente, en el romanticismo, y después de un largo reinado de los hombres en el campo de la danza clásica (Ramos, 2002b), Marie Taglioni, Carlota Grissi, Fanny Elssler, Avdotia Istomina, Amalia Brugnoli, y otras que ahora escapan, afirmaron el rol de la mujer en la danza, a partir de sus hazañas técnicas en el escenario, configuradas por su imagen etérea; el desplazamiento de los hombre en el campo -como intérpretes, porque no en otros roles hasta años después- llevo inclusive a las mujeres a interpretar papeles de hombre. Esta imagen del cuerpo de la bailarina, será la que establezca los cimientos de la bailarina como femenina, elegante y ligera (Pickard, 2015). Cabe mencionar, que, durante el romanticismo, la danza clásica "mostró la creciente fuerza del individualismo burgués, las leyes de la competencia rigieron las relaciones entre bailarines" (Ferreiro, 2005, p. 86). Posteriormente, para la segunda mitad del siglo XIX, la bailarina se hizo atlética: "con músculos y puntas de acero y una técnica cercana a la acrobacia" (Ramos, 2002b, p. 586).

Ya para el siglo XX, el proceso de institucionalización continuó su solidificación, expandiéndose a diferentes latitudes del globo. En el siglo XXI, el bailarín de danza 
clásica escénica juega dentro del escenario con los elementos técnicos y artísticos, a la vez, que se agregan variables de nuestro tiempo, como la tecnología. Se debe decir, que lo presentado es sólo un recorte histórico de la danza clásica escénica, sin embargo, a partir de lo anterior, se tiene información para sustentar la conformación del universo simbólico de la danza clásica, considerando elementos fundamentales como el lenguaje, imagen sobre el cuerpo, tratamiento del cuerpo, mecanismos de control, jerarquías, entre otros símbolos que se vuelven evidentes al observador en una clase de danza clásica escénica o una función.

\section{Puntos de referencia teórica}

La cultura en esta investigación, como se puede adelantar, se comprende desde su concepción semiótica, considerando lo simbólico como "el mundo de las representaciones sociales materializadas en formas sensibles, o también llamadas formas simbólicas" (Giménez, 2005, p. 68); es decir, procesos de emergencia, significación y comunicación del hecho social, inscritos en un tiempo-espacio particular.

Por su parte, el símbolo se aprehende como un conjunto de significados respecto a un signo, el cual se introyecta a través de la experiencia del sujeto. La memoria del sujeto se encuentra con la memoria del colectivo, lo cual, favorece la perpetuación del campo y sus símbolos, pero también deja una pequeña grieta para la creatividad e imaginación del sujeto.

En este entramado, el cuerpo adquiere una función esencial, pues a través de este que el símbolo se abre a la realidad; $y$, por lo tanto, en el cuerpo se pueden obtener indicios sobre los símbolos que se encarnan; el cuerpo se presenta como fuente de significaciones.

Con base en lo anterior, esta comprensión de la cultura se acerca a las proposiciones de Pierre Bourdieu, y es por ello que, el estudio empírico se entreteje a partir de esta teoría, pues permite aprehender la bivalencia del individuo y la sociedad en la práctica social; ideas que se basan en la encarnación del mundo social y la participación del sujeto en esta realidad, como se ha mencionado. Bajo la premisa, el ballet, específicamente se comprende como una práctica social y cultural encarnada.

\section{Danza clásica y teoría bourdiana}

El cuerpo en la danza clásica escénica es una unidad fundamental para la materialización del movimiento comprendido como práctica-, para la incorporación del habitus y para la participación del bailarín en la estructura a través del capital; el cuerpo entonces, se presenta como un elemento que entrelaza la acción y el habitus.
Esta conceptualización del cuerpo se realiza a través de David Le Breton y Marcel Mauss, para quienes el cuerpo es un entretejido del mundo natural del sujeto con la realidad social. Particularmente para Le Breton, el cuerpo se deriva de la conjunción de esta entidad física con la persona y la sociedad, y propone: "las representaciones de la persona y las del cuerpo, corolario de aquellas, están siempre insertas en las visiones del mundo de las diferentes comunidades humanas" (2012, p. 27). Bajo la premisa, resulta pertinente cuestionar sobre el objeto de estudio: ¿qué es el cuerpo? ¿quién es el cuerpo? ¿de dónde provienen aquellos materiales simbólicos que forman el cuerpo?

Por su parte, Marcel Mauss aporta el concepto de técnica corporal, como se ha revisado; el cuerpo en este entendido, será el instrumento primigenio del ser humano, en el cual el habitus y la técnica se corporeiza, se hereda -tradición-, se aprende y reproduce transmisión y adquisición-.

Con base en lo anterior, sobre la dialéctica individuo y sociedad, se puede comprenderque "el movimiento no es inocente: en el cuerpo están impresas las fracturas sociales" (Islas, 1995, p. 167), se desencadenan más preguntas: ¿cómo se mueven? ¿por qué se mueven así?

En otro orden de ideas, pensar el cuerpo de la danza clásica es problematizar una corporalidad singular, pues posee una estilización física particular, que proviene de una larga tradición histórica, y que converge en la sucesión de posiciones y movimientos, que se logran a través de la escolaridad artística; el cuerpo se vuelve objeto y sujeto (Pickard, 2015). Construcción estética que se hereda de los sujetos noveles a los sujetos con mayor antigüedad, construcción histórica pero mutable, que conserva los rasgos del pasado, pero que también muestran la innegable transformación de la imagen.

Ahora bien, el cuerpo de la danza clásica, con base en las proposiciones teóricas y el análisis de la constitución del campo, permite el reconocimiento de símbolos inscritos dentro del cuerpo de la danza clásica, tales como una conceptualización de la persona que danza y sus distinciones respeto a los otros, como el género o la clase social. Un ejemplo de estas inscripciones corporales, es el de la verticalidad, símbolo que deviene de la imagen occidental de belleza y que puede comprenderse a través de la diferenciación entre lo altobueno y lo bajo-malo. Es interesante observar como este símbolo, además de validarse en el campo de forma inicial, a través de una idealización de belleza, ha conllevado a la necesidad de una demostración científicafisiológica de la verticalidad como premisa para la concreción técnica. 
Esta creencia del cuerpo del ballet, muestra una fuerte disposición del habitus en el bailarín (Pickard, 2015), y con ello se hace notar el trato que el bailarín da a su cuerpo, con el propósito de alcanzar este ideal. En este sentido, el cuerpo adquiere la cualidad de maleabilidad, pues se encuentra en permanente construcción (Aalten, 2007), cualidad que también es legitimada en el campo. $Y$ que ciertamente justifica la emergencia de conceptos como la disciplina y el dolor.

Particularmente, en la danza clásica, el proceso de adquisición del habitus inicia en los primeros años del sujeto, durante la formación dancística; lo cual para Pickard (2015) constituye el habitus nuclear del sujeto, pues se encarnan disposiciones en el cuerpo del bailarín en formación (Op. Cit., p. 65). Una vez en la esfera de lo laboral, el habitus del bailarín se materializa en acciones concretas como el ascenso dentro de la jerarquía de una compañía, y con ello, la cristalización de la asimilación del habitus y la manifestación de una herencia de múltiples significaciones históricas; que, a su vez, el sujeto reproduce.

De las líneas anteriores, se puede decir, siguiendo a Pickard (2015), que el núcleo del campo del ballet se organiza con base en la producción del cuerpo del bailarín, la estética del ballet y la construcción de una identidad (Op. Cit., p. 64), es decir, el campo configura una identidad en el bailarín. En este entendido, y siguiendo a Pierre Bourdieu (1997), aquellos sujetos que no posean un habitus para participar en el campo, serán excluidos del campo, y quienes lo posean serán jerarquizados.

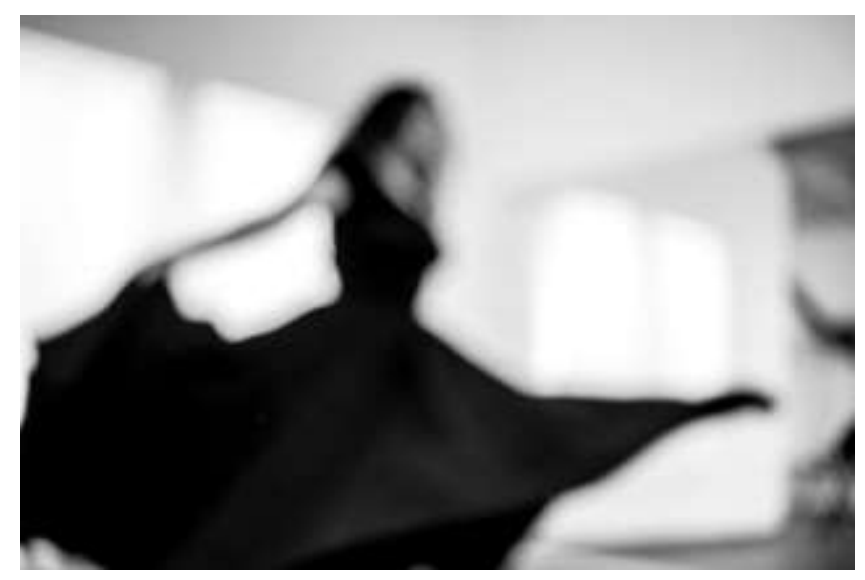

Desdoblamientos a partir de la multiplicidad del cuerpo en la imagen de Diana Áviles Samperio (2020).

\section{Danzando entre la teoría y la realidad}

Dentro de la investigación empírica se concreta la idea de que el habitus no se presenta como algo coherente e integrado (Criado, 2013), sino más bien como trayectorias ondulantes, que al igual que el movimiento posee diferentes trayectorias. Además de esta idea, se debe considerar que lo particular de los bailarines no es el objetivo final, sino aquellos procesos que transcienden la individualidad (Baz, 1994).

\section{Familia y escuela}

El habitus del bailarín inicia su construcción desde la familia, a partir de la transmisión de estrategias para la continuación del ser social de la misma (Bourdieu, 1997); lo anterior, se materializa en elementos como el aporte del capital económico para la formación del bailarín:pago de clases de danza y otras disciplinas corporales, transportación, alimentación, adquisición de zapatillas, vestuario, y otros; que posteriormente se transformará en capital técnico y artístico del bailarín, y que en conjunto le permitirán ingresar al campo. Se debe agregar a lo anterior, que el sustento emocional de la familia es importante en la formación del bailarín durante la niñez.

Posteriormente, el ingreso del sujeto al universo simbólico de la danza durante la escolaridad dibujará otras formas singulares en el habitus del sujeto. En primera instancia, deberá mostrar su talento para ingresar a la escuela de danza o para captar la atención de algún "vigilante del campo" -el concepto de vigilante del campo, busca retornar las construcciones teóricas de Michael Foucault (2003), para hacer referencia a aquellos sujetos dentro del campo, que, debido a su capital, comprimen a otros sujetos a partir de la vigilancia-; lo anterior, con todas las implicaciones objetivas de mostrar y captar la atención, para ser observado y observar.

No obstante, en esta línea de ideas es pertinente cuestionar qué es el talento, para un bailarín es la "habilidad para desempeñar una determinada actividad, pero es natural, porque eso no, nadie te lo da"; pero desde el punto de vista bourdiano, el talento es una construcción de los sujetos inscritos en el campo, que sólo existe a través de la relación con otras propiedades y no es una distinción natural (Bourdieu, 1997).

Ahora bien, la "cuantificación del talento" y su reconocimiento por los vigilantes del campo, conjugado con la edad del sujeto que inicia su formación, determinarán la duración de su escolaridad.

La escuela por su parte, será una institución que coadyuve a la reproducción de la distribución del capital cultural, pues buscará la mayor homogeneidad en los aprendices, y separará a los talentosos de los no talentosos, o en términos bourdianos: "separación entre los alumnos dotados de cantidades desiguales de capital" (Bourdieu, 1997, p. 34). En la escuela, los docentes serán quienes, además, de la transmisión de la técnica corporal, transmitirán al sujeto una forma de ser y pensar en el cuerpo; que, a su vez, se materializarán en elementos 
como disciplina, vigilancia permanente del cuerpo (de forma propia y del otro), y legitimación del dolor.

Por otro lado, cabe decir que aquellos bailarines que iniciaron su formación dancística en la niñez, manifiestan haber tenido experiencias atípicas en relación a sujetos de su edad; una bailarina argumenta: "cuando un niño normalmente está corriendo, pues tú estás sudando, haciendo lagartijas, es como desde chiquito te obligan a ser muy independiente y muy estricto contigo"; en estas ideas, se observa que el sujeto se encuentra en un desarrollo emocional acelerado, en el cual se inscribe el aprendizaje de categorías como la disciplina.

Sobre la disciplina, en la danza la construcción de su significado en singular, pues es un elemento para el sujeto que desee desempeñarse profesionalmente (Pickard, 2015), discurso que se encuentra presente en la mayoría de los bailarines. A partir de este deseo, el bailarín es obediente y cómplice de su propia subordinación, durante la escolaridad respecto al docente, y más adelante respecto a otras figuras de poder como el director de la compañía. En la emergencia de la disciplina, aparece de forma inmediata el deseo-pasión.

\section{De la escuela a la compañía de danza}

Al finalizar la escolaridad, el bailarín que desee ingresar al mercado laboral de la danza clásica escénica, deberá desplegar su habitus y su capital; a través de audiciones o captando la atención de otro vigilante del campo. Una vez dentro del compañía, deberá continuar desarrollando su capital corporal, técnico y artístico; proceso guiado por la imagen corporal del campo de la danza y la participación de los vigilantes, que adquirirán otras formas, como la del director artístico principalmente.

Dentro del campo, en el estudio empírico, se observó que los bailarines aprenden ciertos elementos durante su formación dancística que posteriormente serán puestos en práctica, por ejemplo: "hacer menos, pero con calidad", amor a la danza, pensamiento analítico sobre el movimiento, resiliencia, respeto, bases corporales para el movimiento (aprendido a través de la exigencia), entre otros.

Es interesante el tema de la resiliencia, quizá como una metáfora del cuerpo del bailarín de danza clásica, al cual la técnica le exige una anatomía resiliente; una bailarina argumenta: "muy clara mi autoestima, el no dejarme apachurrar, cada reto que me ponían no de forma agradable, siempre es gracias a mi autoestima y superarlo, es decir okay vamos a trabajar"; en estas palabras, emerge la paradoja del castigo y la superposición a través de la resiliencia.

Una vez dentro de la compañía, el bailarín mejorará de forma importante su capital corporal, debido al entrenamiento permanente, que a su vez favorece, el aumento del capital técnico, y que en conjunto propician el aumento del capital cultural; que, como fórmula matemática, resulta de las horas de clases, de ensayos y en el escenario; otorgándole al bailarín "madurez" respecto a su cuerpo y su utilización, proceso que permite la permanente construcción de la identidad del bailarín. Se debe anotar, que este desarrollo, se ve relacionado con el capital social del sujeto, que se deriva del contacto una gran variedad de bailarines, maestros, ensayadores, coreógrafos, entre otros.

Ahora bien, el habitus y el capital del bailarín determinarán su posición dentro del campo, y con ello dentro de la jerarquía de la compañía; una bailanina comenta: "hay gente que lleva veinte años que se queda en la primera y está bien, porque son muy buenos cuerpos de baile, pero también ha ocurrido, por ejemplo, con una dirección que a mí me tocó, que, a alguien de cuerpo de baile, a los dos años de estar en la compañía lo subieron a primer bailarín". En este comentario se muestra, además, la influencia de la dirección para jerarquizar a los bailarines; pero también, la emergencia del azar, como una dimensión que resulta ser determinante en la trayectoria del bailarín, en cuanto las direcciones artísticas de las compañías son dinámicas.

Desde la visión de los bailarines, el ascenso y permanencia en el campo se encuentra condicionado por aspectos como: fuerza, perseverancia, establecimiento de metas, audacia, hacerse notar, constancia, disciplina, perfeccionamiento técnico, aprendizaje rápido del repertorio, desarrollo cognitivo, desarrollo emocional, agilidad para tomar oportunidades que se presenten, $y$ entrenamiento adicional.

Habrá que decir también, que se observó que los bailarines con mayor tiempo dentro del campo y con una buena posición en la jerarquía, serán quienes transmitan el habitus a los bailarines noveles; una bailarina argumenta: "eres ejemplo para los otros bailarines, eres el que está casi llegando y pues para todos los que están debajo, creo también es nuestra responsabilidad inculcarles todas esas costumbres de respeto a los primeros bailarines, de disciplina, de constancia, de todo eso".

En cuanto a la percepción del bailarín sobre su cuerpo, esta muestra el habitus del sujeto, pero también la fuerza de la institución-compañía en la que se desempeña, de forma genérica se concibe el cuerpo material como estilizado, delgado pero fuerte, ágil, resistente, alargado y proporcionado. Sin embargo, se reconocen compañías donde la presencia de un sujeto -coreógrafo o director artístico- en particular, puede contrarrestar la fuerza de la historia del campo, tal es el caso de una compañía, en la que su fundadora dibujo una imagen del cuerpo del 
bailarín, y la atención la desvió de la materialidad del cuerpo y más bien sobre la expresividad; un bailarín comenta: "no importa si eres moreno, si no eres tal alto, si no tienes las proporciones ideales del ballet clásico, y eso también enriquece a la compañía, que hay cuerpos de todo tipo, a lo mejor no hay gente con sobrepeso, no es algo permitido, pero en la generalidad, lo que la genética te dio, es bienvenida". Cabe anotar, que dentro de esta compañía no existen jerarquías entre los bailarines.

Esta particularidad, es descrita por Wainwright et al. (2006) como habitus institucional del bailarín, que son aquellas disposiciones incorporadas en el habitus del bailarín a partir de su participación en compañías de danza, y con ello la encarnación de símbolos propios de la compañía; por ejemplo: estilo, trabajo de un coreógrafo, imagen del cuerpo, jerarquías, entre otros.

Dentro del campo de la danza, y con base en la teoría del habitus, las luchas de poder surgen de la búsqueda permanente del capital y con ello, de una mejor posición dentro de la estructura, lo cual se puede materializar en competencia y egocentrismo, como se observa en el campo de la danza clásica.

Finalmente, el dolor se presenta como un símbolo que muestra el vínculo entre el individuo y la estructura a través del habitus; esta dimensión se encuentra de forma univoca en la experiencia de los bailarines. El dolor es abordado desde Le Breton, para quien el tratamiento al dolor se aprende durante el entrenamiento de la técnica corporal; si bien el autor lo aborda desde los deportes, es pertinente para pensar la danza. Una bailarina argumenta: "me acuerdo que bailé una temporada de Serenata muy lastimada, el tendón de Aquiles del pie izquierdo, muy lastimada y mi desempeño artístico no fue muy óptimo en la función"; el cuerpo y su memoria, se convierten entonces en testigos privilegiados de la superación del dolor (Op. Cit., p. 259).

Sobre esta línea de ideas, el dolor como símbolo, muestra además el fuerte arraigo de la profesión a la identidad individual del bailarín, pues el "dejar de bailar" produce fisuras en la identidad del bailarín, situación que también se observa cuando el bailarín se retira de la danza; debiendo anotar, que el retiro en la danza clásica escénica, se produce en una edad atípica (a los 40 años aproximadamente). En este sentido, el envejecimiento del cuerpo confronta al bailarín consigo mismo, un bailarín argumenta: "se vuelve difícil, cuando de pronto te das cuenta que ya no puedes seguir haciendo lo que hacías, que el cuerpo ya no te responde de la misma manera"; en el estudio empírico, los bailarines retirados, continúan en el campo de la danza, pero desde la docencia, investigación, creación o dirección.

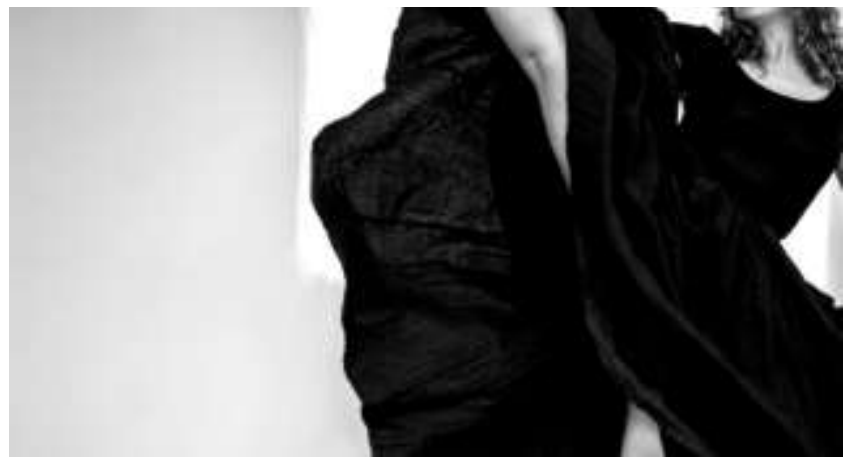

Desdoblamientos a partir de la multiplicidad del cuerpo en la imagen de Diana Áviles Samperio (2020).

\section{Conclusiones}

La cultura se comprende como un conjunto de hechos sociales, a la vez que en ella se entretejen un conjunto de símbolos materiales e in materiales que se inscriben en el cuerpo de los sujetos. La danza clásica como práctica cultural se encarna en los sujetos a través del habitus, el cual lleva consigo el aprendizaje de una técnica corporal -la técnica clásica- y otras proposiciones, el cuerpo del bailarín abraza y expresa el habitus en el campo; y es por ello que las acciones de los sujetos no son gratuitas, sino que hay una razón detrás de estas (Bourdieu, 1997).

Las trayectorias laborales de los bailarines se trazaron a partir de las experiencias de los sujetos en el campo de la danza clásica; experiencias con significados históricos, que explican de dónde vienen y quiénes son; experiencias que permiten entretejer la individualidad y la totalidad, el universo lingüístico y el universo social, la enunciación y la práctica, el pasado y el presente del cuerpo, la emoción y la cognición. Experiencias que danzan para encontrarse, y dibujar un movimiento unísono sobre el campo de la danza clásica escénica.

En este recorrido, destaca la presencia de símbolos que se inscriben en el cuerpo del bailarín como el dolor, la disciplina y la vigilancia permanente, el cuerpo en este sentido se presenta como el vínculo entre lo individual y lo social, que se conforma a través de técnicas corporal y con ello el habitus, el cuerpo para Bourdieu será un "repositorio de disposiciones arraigas y durables, y esta incorporación de nuestra historia, es mostrada por ejemplo en las diferentes posturas que el hombre y la mujer adoptan" (citado en Wainwright et al., 2006, p. 537).

En la formación dancística el cuerpo dócil del sujeto será moldeado por las posturas, los movimientos y los gestos; hasta lograr aquella imagen deseada, imagen que es heredada de los antiguos miembros del campo a los recién llegados, herencia que se inscribe de forma durable en los cuerpos de los bailarines noveles para luchar en el campo de la danza, desplegando estrategias y haciendo uso de su capital-físico, técnico y artístico-. 
El bailarín en esta intersección entre el yo y el otro, la pasión y la disciplina, se transmuta paradójicamente en cuerpo anestesiado, inasible al dolor, pues desde la escuela aprendió que el dolor permite tocar la perfección. Cuerpo acostumbrado a la mirada del otro, pero que no se detiene a mirarse.

Sin embargo, cuerpo placer, que trasciende y se expande en el tiempo, y en la búsqueda de la imagen deseada, juega con el dolor y el placer, develando la encarnación del erotismo (Pickard, 2015). Dialéctica que en el escenario se vuelve evidente, el dolor físico es dejado en las piernas del escenario y mirado con orgullo desde lejos.

Por último, decir que el campo de la danza clásica continua su sedimentación histórica y con ello la producción y despliegue de mecanismos de control para los sujetos que deseen ingresar a él, que se concreta en aspectos como el reconocimiento de una imagen singular del cuerpo de la danza, sistemas filosóficos, criterios que regulan el comportamiento, definición de roles, acciones y objetos simbólicos para la reafirmación de los sujetos, entre otros.

Quedan aún más interrogante y posibilidades, por ejemplo, analizar el habitus en la escuela de danza, y con ello los criterios que guían los procesos de ingreso, permanencia y egreso; realizar trayectorias laborales de bailarines pertenecientes a una sola compañía, para comprender a profundidad las variables respecto al habitus institucional, y el retiro del bailarín de la compañía, la transformación del sujeto, considerando el arraigo de la identidad del sujeto respecto a su profesión.

\section{Referencias}

[1] Aalten, A. (2007). Listening to the dancer's body. Sociological Review, 55,1,109-125. Doi. 10.1111/j.1467-954X.2007.00696.x

[2] Andreella, F. (2010). El cuerpo suspendido. Códigos y símbolos de la danza al principio de la modernidad. México: INBAL.

[3] Baz, M. (1994). Enigmas de la subjetividad y análisis del discurso. Versión. Estudios de Comunicación y Política: Etnografía y Comunicación, 4 , $117-156$

http://ccdoc.iteso.mx/acervo/cat.asp x ?cmn=download \&ID=463\&N=1 .

[4] Berger, P. y Luckmann, T. (2003). La construcción social de la realidad. Argentina: Amorrortu Editores.

[5] Bourdieu, P. (1997). Razones Prácticas. Sobre la teoría de acción. Barcelona: Editorial Anagrama.

[6] Criado, E. (2013). Cabilia: la problemática génesis del concepto de habitus. Revista Mexicana de Sociología, 75, 1, 125-151. http://www.redalyc.og/articulo.oa ?id=32125628007

[7] Dallal, A. (1997). Procesos espontáneos e inducidos en el arte dancístico. Revista Mexicana de Ciencias Sociales y Políticas, 41, 170, 13 33. http://dx.doi.org/10.22201/fcpys.2448492xe.1997.170.49297

[8] Ferreiro, A. (2005). Escenarios rituales. Una aproximación antropológica a la práctica educativa dancística profesional. México:
Colegio de Estudios de Posgrado de la Ciudad de México/CENIDI Danza/INBA/CENART/CONACULTA.

[9] Fernández, M. L. (2007). Cultura y poder en la danza contemporánea. Ensayo sobre una disciplina plebeya en México. Tesis de licenciatura, Escuela Nacionalde Antropología e Historia.

[10] Foucault, M. (2002). Vigilary castigar. Argentina: Siglo XXI Editores.

[11] Giménez, G. (2005). Teoría y análisis de la cultura I. México: CONACULTA E ICOCULT.

[12] Islas, H. (1995). Tecnologías corporales: danza, cuerpo e historia. México: CENIDI Danza/INBA.

[13] Katz, H. (2015). Pala vra que eu uso me incluinela. En Katz,H. (Autor), Um, dois, três, a dança é o pensamento do corpo,pp. 7-61. Belo Horizonte: Fórum Internacional de Dança.

[14] Le Breton, D. (2012). Sobre algunas a mbigüedades. En La sociología del cuerpo,pp. 25-32. Buenos Aires: Ediciones Nueva Visión.

[15] - (1999). Antropología del dolor. Barcelona: Seix Barral S.A.

[16] Mauss, M. (1979). Técnicas y movimientos corporales. En Sociología y antropología, 337-354. Madrid: Editorial Tecnos.

[17] Pickard, A. (2015). Ballet body narratives: pain, pleasure and perfection in embodied identity. Alemania: Peter Lang A.G.

[18] Ramos, M. (2002a). De la fiesta teatral barroca al ballet de acción: profesionalización de los artistas del espectáculo y danza teatral durante el virreinato. En La danza en México. Visiones de cinco siglos. Tomo I: Ensayos históricos y analísticos, pp. 339-370. México: CENIDI Danza/INBA/CONACULTA/Escenología.

[19] - (2002b). Artes escénicas y globalización: movimientos artísticos europeos y formas dancísticas universales en el México decimonónico, 1825-1910. En La danza en México. Visiones de cinco siglos. Tomo I: Ensayos históricos y analísticos, pp. 571-594. México: CENIDI Danza/INBA/CONACULTA/E

[20] Ramos, R. (2009). Una mirada a la formación dancística mexicana (CA. 1919-1945). México: FONCA/INBA/CONACULTA y Grapondi de México.

[21] Solís, M. y Brijandez, S. (2018). Danza y vida económica: experiencias del trabajo creativo en México. Revista Latinoamericana de antropología del trabajo, $4, \quad 2-20$. https://www.academia.edu/37837456/Danza_y_vida_econ\%C3\%B3mica_ experiencias_del_trabajo_creativo_en_M\%C3\%A9xico

[22] Sistema de Información Cultural México. (2018). Creadores y espacios cultura les [datos estadísticos]. https://sic.cultura.gob.mx/index.php

[23] Turner, V. (2008). Antropología del ritual. México: ENAH-INAH.

[24] Wainwright, S., Williams, C. y Turner, B. S. (2006). Varieties of habitus and the embodiment of ballet. Qualitative Research, 6, 4, 535-558. Doi. $10.1177 / 1468794106068023$. 